\title{
Efficacy of B-Cell-Targeted Therapy with Rituximab in Patients with Rheumatoid Arthritis
}

\author{
Jonathan C.W. Edwards, M.D., Leszek Szczepański, M.D., Ph.D., \\ Jacek Szechiński, M.D., Ph.D., Anna Filipowicz-Sosnowska, M.D., Ph.D., \\ Paul Emery, M.D., David R. Close, Ph.D., Randall M. Stevens, M.D., \\ and Tim Shaw, B.Sc.
}

From University College London, London (J.C.W.E.); Medical University School of Lublin, Lublin, Poland (L.S.); University School of Wroclaw, Wroclaw, Poland (J.S.); the Institute of Rheumatology, Warsaw, Poland (A.F.-S.); Leeds Royal Infirmary, Leeds, United Kingdom (P.E.); Roche Products, Welwyn Garden City, Hertfordshire, United Kingdom (D.R.C., T.S.); and Roche, Nutley, N.J. (R.M.S.). Address reprint requests to Professor Edwards at the Centre for Rheumatology, University College London, 4th Fl., Arthur Stanley House, 40-50 Tottenham St., London WIP 9PG, United Kingdom, or at jo.edwards@ucl.ac.uk.

N EnglJ Med 2004;350:2572-81.

Copyright $@ 2004$ Massachusetts Medical Society.
ABSTRACT

BACK GROUND

An open-label study indicated that selective depletion of B cells with the use of rituximab led to sustained clinical improvements for patients with rheumatoid arthritis. To confirm these observations, we conducted a randomized, double-blind, controlled study.

METHODS

We randomly assigned 161 patients who had active rheumatoid arthritis despite treatment with methotrexate to receive one of four treatments: oral methotrexate ( $\geq 10 \mathrm{mg}$ per week) (control); rituximab (1000 mg on days 1 and 15); rituximab plus cyclophosphamide (750 mg on days 3 and 17); or rituximab plus methotrexate. Responses defined according to the criteria of the American College of Rheumatology (ACR) and the European League against Rheumatism (EULAR) were assessed at week 24 (primary analyses) and week 48 (exploratory analyses).

\section{RESULTS}

At week 24, the proportion of patients with 50 percent improvement in disease symptoms according to the ACR criteria, the primary end point, was significantly greater with the rituximab-methotrexate combination (43 percent, $\mathrm{P}=0.005$ ) and the rituximabcyclophosphamide combination ( 41 percent, $\mathrm{P}=0.005$ ) than with methotrexate alone (13 percent). In all groups treated with rituximab, a significantly higher proportion of patients had a 20 percent improvement in disease symptoms according to the ACR criteria (65 to 76 percent vs. 38 percent, $\mathrm{P} \leq 0.025$ ) or had EULAR responses $(83$ to 85 percent vs. 50 percent, $\mathrm{P} \leq 0.004)$. All ACR responses were maintained at week 48 in the rituximab-methotrexate group. The majority of adverse events occurred with the first rituximab infusion: at 24 weeks, serious infections occurred in one patient (2.5 percent) in the control group and in four patients ( 3.3 percent) in the rituximab groups. Peripheral-blood immunoglobulin concentrations remained within normal ranges.

CONCLUSIONS

In patients with active rheumatoid arthritis despite methotrexate treatment, a single course of two infusions of rituximab, alone or in combination with either cyclophosphamide or continued methotrexate, provided significant improvement in disease symptoms at both weeks 24 and 48 . 


\section{$\mathrm{R}$}

HEUMATOID ARTHRITIS IS A SYSTEMIC autoimmune disease that affects approximately 1 percent of the adult population. ${ }^{1}$ It is characterized by chronic inflammation in the synovial membrane of affected joints that ultimately leads to loss of daily function due to chronic pain and fatigue. The majority of patients also have deterioration of cartilage and bone in the affected joints, which may eventually lead to permanent disability. Rheumatoid arthritis is associated with increased morbidity and mortality. ${ }^{2}$

Although the precise pathogenesis of rheumatoid arthritis remains unclear, it has been postulated that multiple exogenous or endogenous antigenic triggers, or both, act in the presence of a background genetic predisposition to initiate a selfperpetuating series of autoimmune responses in the synovial compartment. ${ }^{3,4}$ Many cell populations, including monocytes, macrophages, B cells, T cells, endothelial cells, and fibroblasts, participate in the ongoing inflammatory process. ${ }^{3}$ The precise contribution of B cells to the immunopathogenesis of rheumatoid arthritis is not fully understood, although a number of mechanisms have been proposed. ${ }^{4-6}$ However, strong evidence for a critical role of B cells in rheumatoid arthritis came from a small open-label study of rituximab in combination with cyclophosphamide and corticosteroids. ${ }^{7}$

Rituximab is a genetically engineered chimeric anti-CD20 monoclonal antibody that is approved for the treatment of relapsed or refractory, lowgrade or follicular, CD20+ B-cell non-Hodgkin's lymphoma. CD20 is a B-cell surface antigen that is expressed only on pre-B and mature $B$ cells. It is not present on stem cells and is lost before differentiation of B cells into plasma cells. Therefore, rituximab causes a selective transient depletion of the CD20+ B-cell subpopulation. ${ }^{7}$ To confirm the role of $B$ cells in rheumatoid arthritis, we evaluated the effect of rituximab in patients with active rheumatoid arthritis in a multicenter, randomized, doubleblind, controlled study.

METHODS

\section{PATIENTS}

Patients were recruited from 26 rheumatology centers in 11 countries (Australia, Canada, Israel, and 8 European countries). Eligible patients were at least 21 years of age, fulfilled the revised 1987 American Rheumatism Association criteria, ${ }^{1}$ and had active disease despite treatment with at least $10 \mathrm{mg}$ of methotrexate per week. Active disease was defined by the presence of at least eight swollen and eight tender joints and at least two of the following: a serum C-reactive protein level of at least $15 \mathrm{mg}$ per liter, an erythrocyte sedimentation rate of at least $28 \mathrm{~mm}$ per hour, or morning stiffness lasting longer than 45 minutes. In addition, eligible patients were seropositive for rheumatoid factor, as defined by a plasma rheumatoid factor level of at least 20 IU per milliliter.

Patients were excluded if they had an autoimmune disease other than rheumatoid arthritis (except concurrent Sjögren's syndrome), American Rheumatism Association functional class IV disease, active rheumatoid vasculitis, a history of systemic diseases associated with arthritis, chronic fatigue syndrome, serious and uncontrolled coexisting diseases, active infection, a history of recurrent clinically significant infection or of recurrent bacterial infections with encapsulated organisms, primary or secondary immunodeficiency, or a history of cancer (except basal-cell carcinoma of the skin that had been excised).

Patients were allowed to receive nonsteroidal antiinflammatory drugs at stable doses or corticosteroids at doses that did not exceed $12.5 \mathrm{mg}$ per day of prednisolone (or the equivalent). Concurrent treatment with any disease-modifying antirheumatic drug or any anti-tumor necrosis factor $\alpha$ therapy during the trial was prohibited.

The study was approved by the institutional review board or the ethics committee at each study site. All patients gave written informed consent.

\section{STUDY PROTOCOL}

At study entry, all patients had received methotrexate (as a single disease-modifying antirheumatic drug) for at least 16 weeks. Therapy with methotrexate during the last four weeks before baseline was at a stable dose. Patients were randomly assigned to receive one of four treatments: oral methotrexate at a dose of $10 \mathrm{mg}$ or more per week plus placebos for rituximab and cyclophosphamide (control group), rituximab plus placebos for methotrexate and cyclophosphamide, rituximab plus cyclophosphamide in an intravenous infusion of $750 \mathrm{mg}$ on days 3 and 17 plus placebo for methotrexate, and rituximab plus methotrexate at a dose of $10 \mathrm{mg}$ or more a week plus placebo for cyclophosphamide. In all three groups that received rituximab (MabThera, Roche; Rituxan, Genentech and IDEC Pharmaceuticals), rituximab was administered as a $1000-\mathrm{mg}$ intrave- 
nous infusion on days 1 and 15 . Investigators and patients remained blinded to the assigned study medications.

All groups, including the control group, also received a 17-day course of treatment with corticosteroids. This consisted of intravenous infusions of $100 \mathrm{mg}$ of methylprednisolone before infusions of either rituximab (or the placebo for rituximab) or cyclophosphamide (or the placebo for cyclophosphamide), together with $60 \mathrm{mg}$ per day of oral prednisone on day 2 and days 4 to 7 and $30 \mathrm{mg}$ per day on days 8 to 14 . All patients also received leucovorin calcium (folinic acid) orally as a single 10 -mg dose on day 1 , to counter any undesired effects of methotrexate. During the course of the study, all treatments for rheumatoid arthritis remained stable.

To prevent potential unblinding due to nausea and vomiting associated with the use of cyclophosphamide, it was recommended that all patients be administered an antiemetic agent (granisetron, $2 \mathrm{mg}$ orally) one hour before the infusions of cyclophosphamide or the placebo for cyclophosphamide.

Clinical assessments were performed at baseline (day 1) and at weeks 12, 16, 20, and 24 according to the American College of Rheumatology (ACR) core set of disease-activity measures. These consisted of a count of swollen joints (66 joints evaluated), a count of tender joints (68 joints evaluated), patient's assessment of pain on a scale from 0 (no pain) to 100 (unbearable pain), patient's global assessment of disease activity on a scale from 0 (disease inactive) to 100 (maximal disease activity), physician's assessment of disease activity, patient's assessment of physical function (by means of a health-assessment questionnaire ${ }^{8}$, and laboratory evaluation of acute-phase reactants (serum C-reactive protein level and erythrocyte sedimentation rate).

Laboratory assessments (including complete blood counts and serum biochemical analyses) were performed at screening (three weeks before baseline), on days $1,3,15$, and 17 , and at weeks 4, 8, 12, 16, 20, and 24. At selected visits, levels of CD19+ $\mathrm{B}$ cells and $\mathrm{CD} 3+, \mathrm{CD} 4+$, and $\mathrm{CD} 8+\mathrm{T}$ cells were measured by fluorescence-activated cell sorting, and immunoglobulin (IgG, IgA, and IgM) concentrations and rheumatoid factor levels were measured by nephelometry. Once rituximab is present in the plas$\mathrm{ma}$, it interferes with the flow cytometry in the assessment of CD20. Consequently, in order for the levels of B cells to be assessed, a separate marker is required. CD19 is a surface antigen and is present on B cells and was the marker used for B cells after the exposure of plasma to rituximab. To investigate the effect of selective B-cell depletion on acquired immunity, antitetanus antibody titers were assessed at baseline and at week 24 . Samples were taken at baseline (before the dose of study medication, on day 1) and at week 24 for analysis of human antichimeric antibodies against rituximab with the use of an enzyme-linked immunosorbent bridging assay (Genentech).

Adverse events were recorded at each visit. A serious adverse event was defined as an event that was fatal, was life-threatening, required hospitalization or prolongation of existing hospitalization (with the exception of hospitalization for exacerbations of articular or periarticular manifestations of rheumatoid arthritis), resulted in persistent or substantial disability or incapacity or in a congenital anomaly or birth defect, or was medically significant or required intervention to prevent any of the outcomes mentioned.

Additional follow-up of patients, including assessments of efficacy, laboratory values, and safety, was conducted at regular intervals up to 48 weeks. Personnel at all sites remained blinded to treatment during this follow-up.

\section{CLINICAL OUTCOME MEASURES}

The primary end point of the study was the proportion of patients with an ACR 50 response at week 24. An ACR 50 response was defined as an improvement of at least 50 percent from baseline in counts of both tender and swollen joints, as well as in three of the five remaining disease-activity measures of the ACR core set: physician's assessment of disease activity, patient's assessment of disease activity, patient's assessment of pain, patient's assessment of physical function (by means of the health-assessment questionnaire), and the value for one acutephase reactant (either serum C-reactive protein level or erythrocyte sedimentation rate). ${ }^{9}$

Secondary outcomes included ACR 20 and ACR 70 responses ( 20 percent and 70 percent improvement, respectively, according to the ACR criteria), a change in the disease-activity score (which includes the physician's assessment of 28 joints and the patient's self-assessment of disease activity), ${ }^{10}$ and the response according to the criteria of the European League against Rheumatism (EULAR response). ${ }^{11}$

\section{STATISTICAL ANALYSIS}

Sample-size calculations were based on the assumption that the proportion of patients continuing to 
receive only methotrexate and achieving an ACR 50 response at week 24 would be 5 percent and that the proportion of patients in any of the rituximab treatment groups would be 30 percent. On the basis of these assumptions and with the use of Fisher's exact test with a two-sided significance level of 0.05 , we calculated that a sample of 40 patients per treatment group would provide the study with 82 percent power to detect a difference between the two proportions.

The primary analyses were based on the intention-to-treat principle. For patients who withdrew before week 24, a last-observation-carried-forward method of imputation was applied. Statistical analyses (with the two-sided Fisher's exact test) were performed only for comparisons of each rituximab group with the control group. Exploratory secondary analyses were performed for ACR response rates at week 48 with use of a nonresponder imputed rule for all patients who withdrew before that time.

Roche was the study sponsor and was responsible for data collection. Statistical analyses were conducted by suitably qualified statisticians who were employees of the sponsor. The trial protocol was designed jointly by the lead clinical investigator (Dr. Edwards) and the sponsor. All the authors had access to and involvement in the interpretation of the data, as well as input into and control over the content of this manuscript (supervised by Dr. Edwards).

\section{RESULTS}

\section{CHARACTERISTICS OF THE PATIENTS}

A total of 161 patients were recruited into the study. The baseline characteristics and measures of disease activity were similar in the four treatment groups (Table 1). The patients had long-standing and highly active disease, as shown by a high mean number of swollen and tender joints, elevated values for acute-phase reactants, and a high mean disease-activity score. The median dose of methotrexate at study entry was 12.5 to $15 \mathrm{mg}$ per week.

All patients who underwent randomization received at least one dose of their assigned medication and had at least one follow-up assessment after baseline. Therefore, the intention-to-treat and safety populations were identical and consisted of all 161 patients who entered the study. Ten patients withdrew from the study before week 24 (Fig. 1). Nine of these 10 patients did not have ACR responses; 1 patient in the rituximab-cyclophosphamide group had an ACR 20 response before an adverse event led to early withdrawal.

\section{CLINICAL EFFICACY}

On the basis of the primary end point of an ACR 50 response at week 24 , the regimens of rituximab in combination with either methotrexate or cyclophosphamide resulted in levels of response that were significantly higher $(\mathrm{P}=0.005)$ than the levels in

\begin{tabular}{|c|c|c|c|c|}
\hline Characteristic & $\begin{array}{l}\text { Methotrexate Group } \\
\qquad(\mathrm{N}=40)\end{array}$ & $\begin{array}{l}\text { Rituximab Group } \\
\qquad(\mathrm{N}=40)\end{array}$ & $\begin{array}{c}\text { Rituximab- } \\
\text { Cyclophosphamide } \\
\text { Group } \\
(\mathrm{N}=41)\end{array}$ & $\begin{array}{c}\text { Rituximab- } \\
\text { Methotrexate } \\
\text { Group } \\
(\mathrm{N}=40)\end{array}$ \\
\hline Age (yr) & $54 \pm 11$ & $54 \pm 10$ & $53 \pm 10$ & $54 \pm 12$ \\
\hline Female sex (\%) & 80 & 73 & 83 & 75 \\
\hline Duration of disease (yr) & $11 \pm 7$ & $9 \pm 6$ & $10 \pm 6$ & $12 \pm 7$ \\
\hline $\begin{array}{l}\text { Previous disease-modifying anti- } \\
\text { rheumatic drugs (no.) }\end{array}$ & $2.6 \pm 1.3$ & $2.5 \pm 1.6$ & $2.6 \pm 1.4$ & $2.5 \pm 1.4$ \\
\hline Swollen joints (no.) & $19 \pm 10$ & $21 \pm 11$ & $19 \pm 10$ & $23 \pm 13$ \\
\hline Tender joints (no.) & $32 \pm 13$ & $34 \pm 15$ & $33 \pm 14$ & $32 \pm 16$ \\
\hline Serum C-reactive protein ( $\mathrm{mg} /$ liter) & $32 \pm 43$ & $26 \pm 22$ & $40 \pm 40$ & $29 \pm 32$ \\
\hline $\begin{array}{l}\text { Erythrocyte sedimentation rate } \\
\quad(\mathrm{mm} / \mathrm{hr})\end{array}$ & $52 \pm 32$ & $47 \pm 23$ & $55 \pm 29$ & $53 \pm 23$ \\
\hline Disease-activity score & $6.9 \pm 0.75$ & $6.8 \pm 0.97$ & $6.9 \pm 0.84$ & $6.8 \pm 0.92$ \\
\hline
\end{tabular}

* Plus-minus values are means \pm SD. The disease-activity score was defined according to the European League against Rheumatism criteria. 


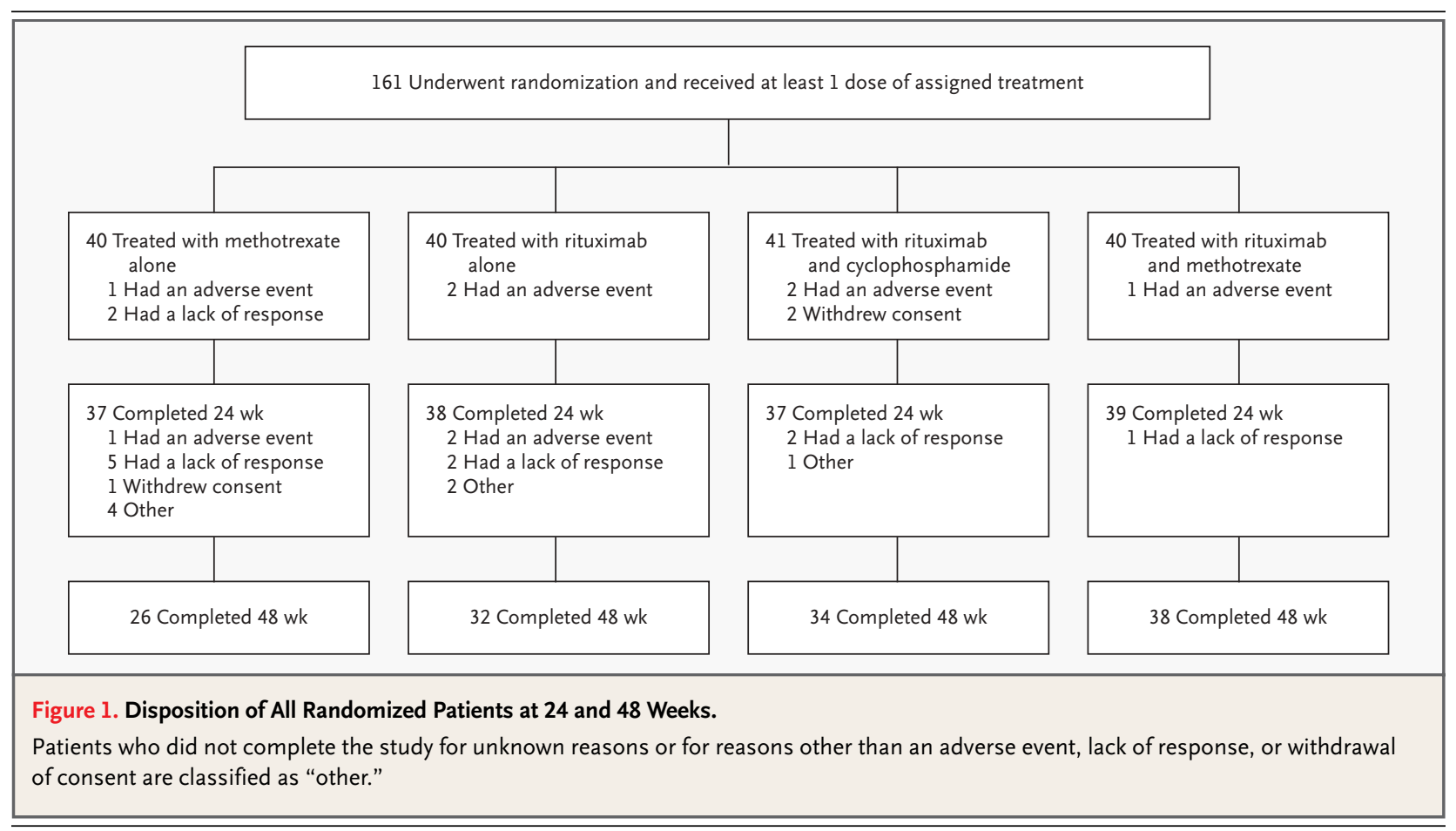

the control group (Fig. 2). The ACR 50 response in the rituximab-monotherapy group was numerically higher than the response in the control group (which received only methotrexate) but the difference did not reach statistical significance $(\mathrm{P}=0.059)$. The proportions of patients with ACR 20 and ACR 70 responses at week 24 were higher in the rituximab groups than in the control group, with statistically significant increases in the frequency of ACR 20 responses in all rituximab groups $(\mathrm{P} \leq 0.025)$ and ACR 70 responses in the rituximab-methotrexate group $(\mathrm{P}=0.048)$.

The mean change from baseline in the diseaseactivity score at week 24 showed significant improvement over methotrexate alone in all rituximab groups $(\mathrm{P} \leq 0.002)$ (Table 2). Furthermore, a significantly higher proportion of patients in the rituximab groups than in the control group responded to treatment, as defined by EULAR criteria $(\mathrm{P} \leq 0.004)$. In addition, 20 to 24 percent of patients receiving rituximab had a good EULAR response at week 24 , as compared with 5 percent of patients receiving methotrexate alone.

Exploratory analyses of ACR responses at week 48 (Fig. 2) showed ACR 70, ACR 50, and ACR 20 responses in 0 percent, 5 percent, and 20 percent of patients in the methotrexate control group, respec- tively, as compared with 15 percent, 35 percent, and 65 percent of patients in the rituximab-methotrexate group $(\mathrm{P}=0.03, \mathrm{P}=0.002$, and $\mathrm{P}<0.001$, respectively). In the rituximab-cyclophosphamide group, 27 percent and 49 percent of patients had ACR 50 and ACR 20 responses, respectively ( $\mathrm{P}=0.01$ for both comparisons). All other comparisons of ACR responses at week 48 favored rituximab therapy but did not reach statistical significance.

\section{PHARMACODYNAMIC OUTCOMES AT WEEK 24}

Rituximab treatment was associated with nearly complete depletion of peripheral-blood B cells, which lasted throughout the 24-week study period (Fig. 3A). Conversely, numbers of B cells (CD19+ cells) first declined and then remained stable in the control group. An initial decline and subsequent rebound were also seen in T-cell populations (CD3+, $\mathrm{CD} 4+$, and CD8+) in all treatment groups. Such effects are most likely associated with the use of corticosteroids during the initial phase of the study. ${ }^{7}$ Despite depletion of B cells, levels of immunoglobulins did not change substantially (mean values remained within normal ranges for IgG, IgM, and IgA isotypes), and there was no effect on antitetanus antibody titers (Table 2).

Rituximab treatment was associated with a large 
Figure 2. American College of Rheumatology Clinical Responses at Weeks 24 and 48.

ACR 20 denotes at least a 20 percent improvement in disease symptoms according to the American College of Rheumatology (ACR) core set of outcome measures, $A C R 50$ a 50 percent improvement, and ACR 70 a 70 percent improvement. $P$ values are for comparisons with the methotrexate-monotherapy (control) group.

and rapid decrease in rheumatoid factor levels (Fig. $3 \mathrm{~B})$. This reduction was pronounced and was maintained at week 24 . Conversely, treatment with methotrexate alone was initially associated with a modest decrease in rheumatoid factor level. However, this decrease was transient, and values returned to baseline by week 24 . The initial decrease may be related to the short course of corticosteroids given during the initial phase of the study.

\section{ADVERSE EVENTS}

During the primary 24-week trial period, six patients withdrew early owing to adverse events. Two of these withdrawals were due to an exacerbation of rheumatoid arthritis (one in the control group and one in the rituximab-cyclophosphamide group). The other four events were hypotension and bronchopneumonia in the rituximab-monotherapy group, staphylococcal septicemia in the rituximabcyclophosphamide group, and renal impairment (a focal lesion on the left kidney of a patient with preexisting nephrolithiasis) in the rituximab-methotrexate group.

The treatment groups had a similar overall incidence of adverse events, with 73 to 85 percent of patients reporting at least one event; 30 to 45 percent of patients in each group had events associated with the first infusion (Table 3). The majority (85 to 90 percent) of adverse events associated with rituximab infusions were characterized as mild or moderate. The following adverse events generally occurred during or within 24 hours after the first infusion of rituximab and tended to be less frequent with the subsequent infusion: transient hypotension or hypertension, cough, pruritus, and rash.

During the initial 24 weeks, a total of 16 serious adverse events were reported in 14 patients, with the highest incidence among patients receiving rituximab plus cyclophosphamide (Table 3). Serious infections occurred in one patient (2.5 percent) in the control group and in a total of four patients (3.3 percent) in the rituximab groups (two patients in the

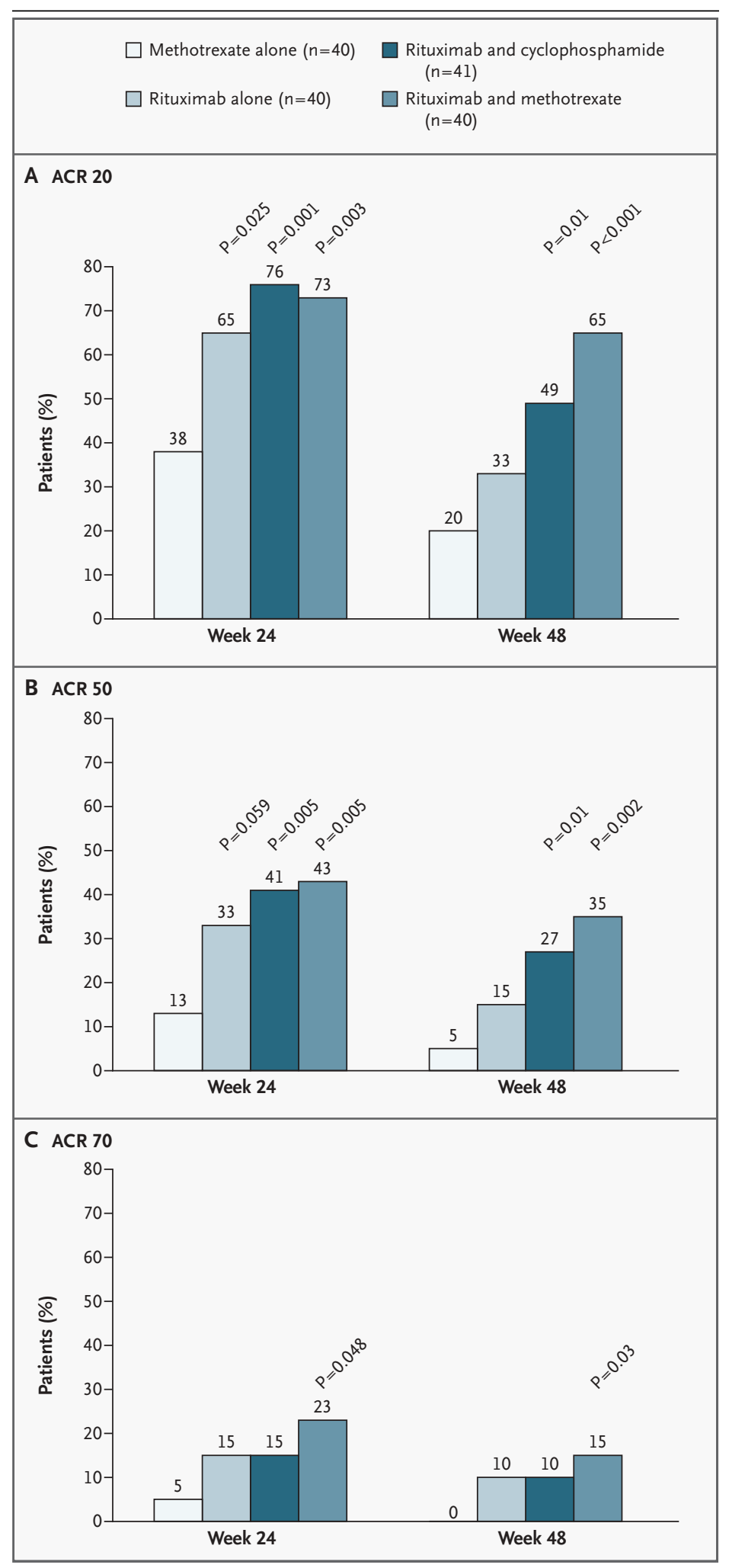




\begin{tabular}{|c|c|c|c|c|}
\hline Variable & $\begin{array}{l}\text { Methotrexate Group } \\
\qquad(\mathrm{N}=40)\end{array}$ & $\begin{array}{l}\text { Rituximab Group } \\
\quad(N=40)\end{array}$ & $\begin{array}{c}\text { Rituximab- } \\
\text { Cyclophosphamide } \\
\text { Group } \\
(\mathrm{N}=41)\end{array}$ & $\begin{array}{c}\text { Rituximab- } \\
\text { Methotrexate Group } \\
(\mathrm{N}=40)\end{array}$ \\
\hline $\begin{array}{l}\text { Change in disease-activity } \\
\text { score }\end{array}$ & $-1.3 \pm 1.2$ & $\begin{array}{c}-2.2 \pm 1.4 \\
(-1.49 \text { to }-0.31) \dagger\end{array}$ & $\begin{array}{c}-2.6 \pm 1.5 \\
(-1.93 \text { to }-0.67) \div\end{array}$ & $\begin{array}{c}-2.6 \pm 1.3 \\
(-1.88 \text { to }-0.72) \div\end{array}$ \\
\hline $\begin{array}{l}\text { Moderate or good EULAR } \\
\text { response (\%) }\end{array}$ & 50 & $85 \dagger$ & $85 \pi$ & 839 \\
\hline Change in $\mathrm{lgG}(\mathrm{mg} / \mathrm{ml})$ & $-0.7 \pm 3.1$ & $-1.1 \pm 2.6$ & $-1.9 \pm 2.2$ & $-1.9 \pm 3.1$ \\
\hline Change in $\mathrm{IgA}(\mathrm{mg} / \mathrm{ml})$ & $-0.1 \pm 0.72$ & $-0.2 \pm 0.74$ & $-0.4 \pm 0.42$ & $-0.6 \pm 0.7$ \\
\hline Change in $\operatorname{lgM}(\mathrm{mg} / \mathrm{ml})$ & $+0.0 \pm 0.37$ & $-0.4 \pm 0.37$ & $-0.5 \pm 0.3$ & $-0.6 \pm 0.72$ \\
\hline $\begin{array}{l}\text { Change in antitetanus anti- } \\
\text { body titer }\end{array}$ & $+0.0 \pm 0.6$ & $-0.1 \pm 0.5$ & $+0.0 \pm 0.4$ & $-0.1 \pm 0.6$ \\
\hline \multicolumn{5}{|c|}{$\begin{array}{l}\text { * Plus-minus values are means } \pm S D \text {, and values in parentheses are } 95 \text { percent confidence intervals for the difference in } \\
\text { the mean change between the rituximab treatment groups and the control (methotrexate-monotherapy) group. } \\
\dagger P=0.002 \text { for the comparison with the methotrexate group. } \\
+P<0.001 \text { for the comparison with the methotrexate group. } \\
\int P=0.001 \text { for the comparison with the methotrexate group. } \\
\qquad P=0.004 \text { for the comparison with the methotrexate group. }\end{array}$} \\
\hline
\end{tabular}

rituximab-monotherapy group and two in the rituximab-cyclophosphamide group). Of these four patients, two had septic arthritis, one of whom also had septicemia owing to Staphylococcus aureus infection. The third patient, who had a history of pseudomonas infection and bronchiectasis, had two episodes of Pseudomonas aeruginosa pneumonia. Fatal bronchopneumonia developed in the fourth patient, who received rituximab alone. No causative organism was isolated in this patient, who had a concomitant cardiac condition (ischemic or vascular heart disease) that may have contributed to the patient's death. The infection in the patient in the control group was a corneal abscess.

During the extended observation to week 48, a further three patients withdrew owing to adverse events: one in the control group (the nature of the adverse event was not recorded) and two in the rituximab monotherapy group (exacerbation of rheumatoid arthritis in one patient and rash in the other). The profile of adverse events reported remained consistent with those observed during the initial 24 weeks (Table 3). There were six additional serious adverse events, including two serious infections (gastroenteritis in a patient who had received rituximab alone, and pyelonephritis in a patient receiving rituximab with methotrexate).

Human antichimeric antibodies developed in only 5 of 117 patients ( 4.3 percent) in the rituximab groups. No specific clinical manifestations were observed in those patients.

\section{DISCUSSION}

In this multicenter, randomized, double-blind, controlled study of a selective depletion of B cells in the treatment of active rheumatoid arthritis, a single short course of rituximab (two infusions, on days 1 and 15), either alone or in combination with cyclophosphamide or continuing methotrexate, provided patients with significant improvements in disease symptoms. At 24 weeks, the proportion of patients who had at least a 50 percent improvement in disease symptoms (ACR 50, the primary end point) was substantially greater in all the rituximab regimens than in the methotrexate (control) group. All the rituximab groups also had a significantly higher proportion of patients who had ACR 20 responses than in the control group, and a significantly higher percentage of patients treated with rituximab plus methotrexate had an ACR 70 response. Furthermore, 83 to 85 percent of patients treated with rituximab had a moderate or good response according to EULAR criteria, as compared with 50 percent of patients in the control group $(\mathrm{P} \leq 0.004)$. The mean decline from baseline in the disease-activity score and the rheumatoid factor level at week 24 was also significantly greater in the rituximab 
groups. Subsequent exploratory analyses ${ }^{12}$ with use of data from an extended observation period showed that pronounced ACR responses remained evident in the rituximab groups 48 weeks after a single course of treatment.

In this study, all patients, including those in the control group, received a short course of corticosteroids, which are known to have strong antiinflammatory effects in patients with rheumatoid arthritis. In the original open-label study, in which rituximab was given in combination with cyclophosphamide and corticosteroids, it was found that corticosteroids may contribute to B-cell death by encouraging apoptosis or direct cytolysis. ${ }^{7}$ As shown in previous studies, ${ }^{7,13}$ the corticosteroids were unlikely to have affected the disease outcomes at week 24 in our trial; however, determining the need for concomitant corticosteroids requires further study.

These data clearly identify B cells as key contributors to the immunopathogenesis of rheumatoid arthritis. Although their precise role is not clear, there are several mechanisms that could profoundly influence the disease process. ${ }^{4-6,14,15} \mathrm{~B}$ cells may function as antigen-presenting cells and provide important costimulatory signals required for CD4+ T-cell clonal expansion and effector functions. ${ }^{16,17}$ In addition, it is known that the synovial membrane in patients with rheumatoid arthritis contains an abundance of plasma cells (derived from B cells) that produce rheumatoid factor and that positivity for rheumatoid factor is associated with more aggressive articular disease, a higher frequency of extraarticular manifestations, and increased mortality. ${ }^{18,19}$ Immune complexes that contain rheumatoid factor bind to Fc receptors on macrophages in the synovial membrane, inducing the release of proinflammatory cytokines, such as tumor necrosis factor $\alpha{ }^{4,20}$ Rheumatoid factor may also be a self-perpetuating stimulus for B cells, potentially leading to activation of and antigen presentation to $\mathrm{T}$ helper cells, which could be mechanistically responsible for further production of rheumatoid factor. ${ }^{4}$ Finally, although T-cell activation is considered to be a key component of the pathogenesis of rheumatoid arthritis, recent evidence indicates that such activation depends on the presence of B cells. ${ }^{16}$

The overall safety profile observed in this study was consistent with that reported previously with rituximab in patients with lymphoma. ${ }^{21}$ Adverse events occurred most frequently with the first infusion. Although the events that occurred during infusions were similar to those that occur in non-
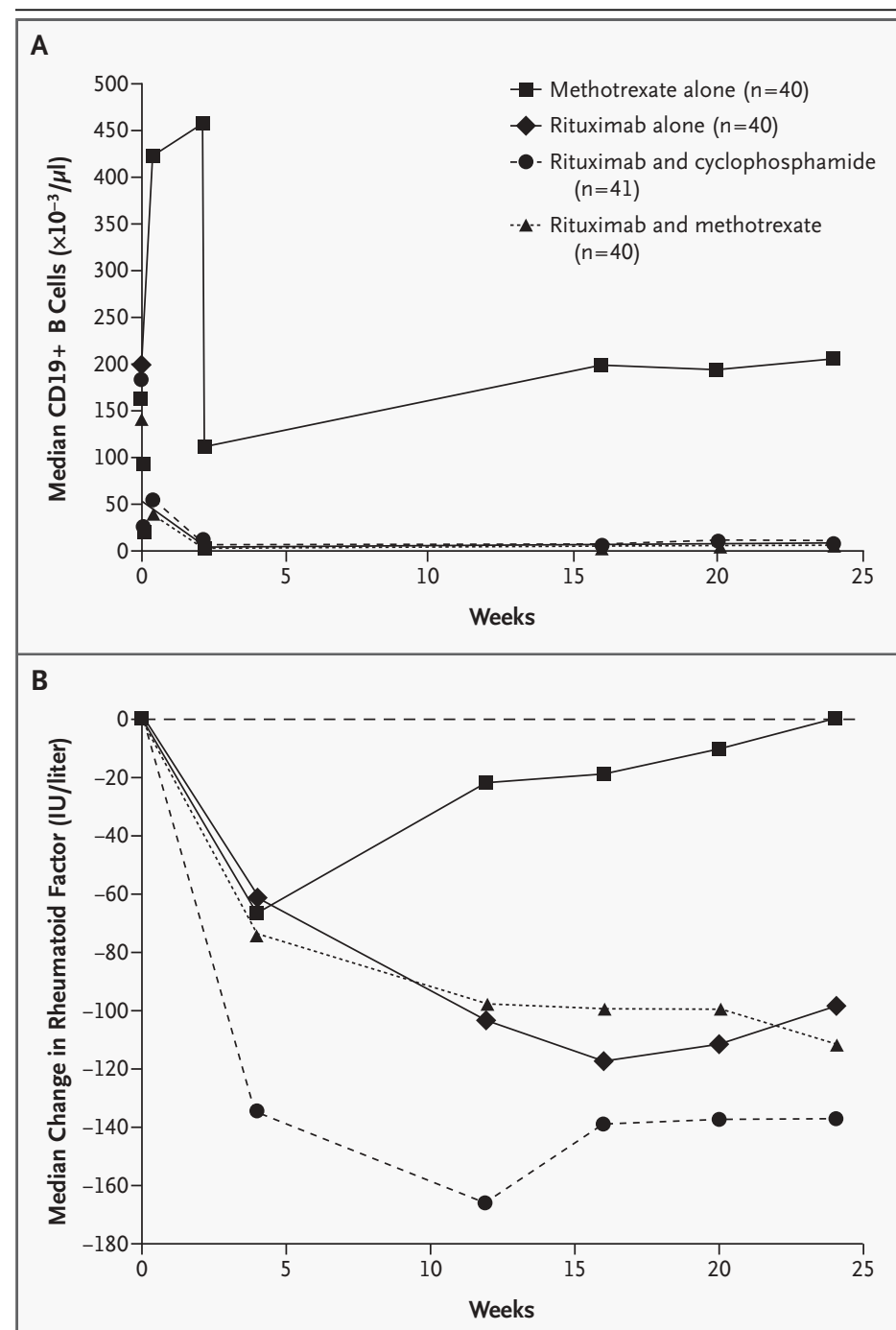

Figure 3. Median Levels of Peripheral CD19+ B Cells and Median Changes in Levels of Total Rheumatoid Factor during the 24-Week Study Period.

Panel A shows the levels of peripheral CD19+ B cells during the study period, and Panel $B$ shows the median change in total rheumatoid factor.

Hodgkin's lymphoma, the incidence and severity of these adverse events seem to be reduced in patients with rheumatoid arthritis. From 70 to 80 percent of patients with non-Hodgkin's lymphoma report adverse events during their first infusion, ${ }^{21}$ as compared with just 36 percent of patients in this study. The reasons for this difference are unknown but could be due to either lower levels of CD20+ lymphocytes in patients with rheumatoid arthritis or premedication with corticosteroids.

The groups receiving rituximab had profound and prolonged depletion of peripheral-blood 


\begin{tabular}{|c|c|c|c|c|}
\hline Adverse Event & $\begin{array}{l}\text { Methotrexate Group } \\
\qquad(\mathrm{N}=40)\end{array}$ & $\begin{array}{l}\text { Rituximab Group } \\
\qquad(\mathrm{N}=40)\end{array}$ & $\begin{array}{c}\text { Rituximab- } \\
\text { Cyclophosphamide } \\
\text { Group } \\
(\mathrm{N}=41)\end{array}$ & $\begin{array}{c}\text { Rituximab- } \\
\text { Methotrexate Group } \\
(\mathrm{N}=40)\end{array}$ \\
\hline & \multicolumn{4}{|c|}{ no. of patients (\%) } \\
\hline $\begin{array}{l}\text { Any event } \\
\text { Up to week } 24 \\
\text { Up to week } 48\end{array}$ & $\begin{array}{l}32(80) \\
34(85)\end{array}$ & $\begin{array}{l}32(80) \\
36(90)\end{array}$ & $\begin{array}{l}30(73) \\
35(85)\end{array}$ & $\begin{array}{l}34(85) \\
35(88)\end{array}$ \\
\hline $\begin{array}{l}\text { Serious adverse event } \\
\text { Up to week } 24 \\
\text { Up to week } 48\end{array}$ & $\begin{array}{l}3(8) \\
4(10)\end{array}$ & $\begin{array}{l}2(5) \\
4(10)\end{array}$ & $\begin{array}{l}6(15) \\
7(17)\end{array}$ & $\begin{array}{l}3(8) \\
4(10)\end{array}$ \\
\hline $\begin{array}{c}\text { Any event associated with } \\
\text { the first infusion }\end{array}$ & $12(30)$ & $18(45)$ & $13(32)$ & $13(33)$ \\
\hline Specific event** & & & & \\
\hline Hypotension $†$ & $7(18)$ & $12(30)$ & $12(29)$ & $7(18)$ \\
\hline $\begin{array}{l}\text { Exacerbation of rheu- } \\
\text { matoid arthritis }\end{array}$ & $16(40)$ & $6(15)$ & $6(15)$ & $2(5)$ \\
\hline Hypertension'† & $6(15)$ & $6(15)$ & $3(7)$ & $10(25)$ \\
\hline Nasopharyngitis & $6(15)$ & $4(10)$ & $2(5)$ & $4(10)$ \\
\hline Arthralgia & $3(8)$ & $3(8)$ & $1(2)$ & $4(10)$ \\
\hline Rash & $1(3)$ & $4(10)$ & $4(10)$ & $1(3)$ \\
\hline Back pain & $2(5)$ & $4(10)$ & $3(7)$ & 0 \\
\hline Cough & 0 & $5(13)$ & $1(2)$ & $2(5)$ \\
\hline Pruritus & 0 & $4(10)$ & $4(10)$ & 0 \\
\hline Nausea & $1(3)$ & $2(5)$ & $4(10)$ & 0 \\
\hline Dyspnea & 0 & $4(10)$ & 0 & 0 \\
\hline
\end{tabular}

* Adverse events that occurred in at least 10 percent of patients in any treatment group up to and including week 24 are shown.

$\dagger$ A change of more than $30 \mathrm{~mm} \mathrm{Hg}$ in systolic or diastolic blood pressure from the pressure at screening was classified as hypotension or hypertension.

$\mathrm{B}$ cells, which raises the question of whether these patients may be more susceptible to infection. However, at weeks 24 and 48, the overall incidence of infection was similar in the control group and the rituximab groups, with no obvious pattern in types of causative organism. Immunoglobulin levels appeared to be only minimally affected, and antitetanus antibody titers (as a measure of previously acquired immunity) were unaffected. By week 24, serious infections had occurred in one patient (2.5 percent) in the control group and in a total of four patients ( 3.3 percent) in the rituximab groups. Two additional serious infections were reported during the extended observation period of 48 weeks. Fatal bronchopneumonia developed in one patient in the rituximab monotherapy group, who had a concomitant cardiac condition (no causative organism was isolated). The incidence of infection will require careful monitoring in future studies, as will longterm effects on acquired immunity.

In conclusion, this study provides clear evidence that a single short course of rituximab provides significant, clinically meaningful benefits to patients with active rheumatoid arthritis. Rates of ACR responses were maintained over a prolonged observation period. This finding provides valuable insight into the role of $\mathrm{B}$ cells in this progressively disabling disease.

Supported by Roche.

Drs. Edwards, Szczepański, Szechiński, Filipowicz-Sosnowska, and Emery report having received grant support from F. HoffmannLa Roche. Drs. Edwards and Emery report having served as consultants to F. Hoffmann-La Roche. Dr. Szechiński reports having served as a consultant to Schering-Plough and having been a member of a speakers' bureau sponsored by Aventis. Dr. Filipowicz-Sosnowska reports having been a member of speakers' bureaus sponsored by Aventis, Merck, and Wyeth. Dr. Close and Mr. Shaw are employees of Roche Products. Dr. Stevens is employed by Roche. 
A P PEN DIX

In addition to the authors, the following investigators and institutions participated in the study: M. Nahir (Rambam Medical Center, Haifa, Israel), H.-D. Stahl (University of Leipzig, Leipzig, Germany), K. Pavelka (Institute of Rheumatology, Prague, Czech Republic), T. Sheeran (Cannock Chase Hospital, Cannock, United Kingdom), I. Rosner (Bnei-Zion Medical Center, Haifa, Israel), R. Cattaneo (Spedali Civili and University of Brescia, Brescia, Italy), J.L. Marenco (Valme University Hospital, Seville, Spain), I. Zimmermann-Górska (Medical University of Poznań, Poznań, Poland), B. Seriolo (University Hospital of Genoa, Genoa, Italy), C. Mussini (Azienda Ospedaliera Policlinico di Modena, Modena, Italy), E. Martín-Mola (Hospital Universitario La Paz, Madrid), L. Carreño (Hospital Universitario Gregorio Marañón, Madrid), S. Bustabad (University Hospital of the Canary Islands, Tenerife, Spain), P. Dawes (Haywood Hospital, Stoke-on-Trent, United Kingdom), R. Day (Clinical Trials Centre, Darlinghurst, Australia), M. Malaise (University of Liège, Liège, Belgium), E.M. Veys (University Hospital of Ghent, Ghent, Belgium), B. Haraoui (University of Montreal, Montreal), W. Bolten (Rheumatology Clinic, Wiesbaden, Germany), F.C. Breedveld (Leiden University Medical Center, Leiden, Germany), and R. Marcolongo (University of Siena, Siena, Italy).

REFERENCES

1. Lawrence RC, Helmick CG, Arnett FC, et al. Estimates of the prevalence of arthritis and selected musculoskeletal disorders in the United States. Arthritis Rheum 1998;41: 778-99.

2. Pincus T, Callahan LF. Reassessment of twelve traditional paradigms concerning the diagnosis, prevalence, morbidity and mortality of rheumatoid arthritis. Scand J Rheumatol Suppl 1989;79:67-96.

3. Panayi GS. The immunopathogenesis of rheumatoid arthritis. Br J Rheumatol 1993; 32:Suppl 1:4-14.

4. Edwards JC, Cambridge G, Abrahams VM. Do self-perpetuating B lymphocytes drive human autoimmune disease? Immunology 1999;97:188-96.

5. Gause A, Berek C. The role of B cells in the pathogenesis of rheumatoid arthritis: potential implications for treatment. BioDrugs 2001;15:73-9.

6. Zhang Z, Bridges SL Jr. Pathogenesis of rheumatoid arthritis: role of B lymphocytes. Rheum Dis Clin North Am 2001;27:335-53. 7. Edwards JC, Cambridge G. Sustained improvement in rheumatoid arthritis following a protocol designed to deplete $\mathrm{B}$ lymphocytes. Rheumatology (Oxford) 2001;40: 205-11.

8. Fries JF, Spitz P, Kraines RG, Holman HR. Measurement of patient outcome in arthritis. Arthritis Rheum 1980;23:137-45.
9. Felson DT, Anderson JJ, Boers M, et al. The American College of Rheumatology preliminary core set of disease activity measures for rheumatoid arthritis clinical trials. Arthritis Rheum 1993;36:729-40.

10. Prevoo ML, van 't Hof MA, Kuper HH, van Leeuwen MA, van de Putte LB, van Rie PL. Modified disease activity scores that include twenty-eight-joint counts: development and validation in a prospective longitudinal study of patients with rheumatoid arthritis. Arthritis Rheum 1995;38:44-8. 11. Van Gestel AM, Anderson JJ, van Riel PL, et al. ACR and EULAR improvement criteria have comparable validity in rheumatoid arthritis trials. J Rheumatol 1999;26:705-11. 12. Emery P, Szczepanski L, Szechinski J, et al. Sustained efficacy at 48 weeks after single treatment course of rituximab in patients with rheumatoid arthritis. Arthritis Rheum 2003;48:Suppl:S439. abstract.

13. Leandro MJ, Edwards JC, Cambridge G. Clinical outcome in 22 patients with rheumatoid arthritis treated with B lymphocyte depletion. Ann Rheum Dis 2002;61:883-8. 14. Reparon-Schuijt CC, van Esche WJ, van Kooten C, et al. Presence of a population of CD20+, CD38- B lymphocytes with defective proliferative responsiveness in the synovial compartment of patients with rheumatoid arthritis. Arthritis Rheum 2001;44. 2029-37.
15. Shiokawa S, Matsumoto N, Nishimura J. Clonal analysis of B cells in the synovia membrane of patients with rheumatoid arthritis. Scand J Rheumatol 2003;32:12-8.

16. Takemura S, Klimiuk PA, Braun A, Goronzy JJ, Weyand CM. T cell activation in rheumatoid synovium is B cell dependent. J Immunol 2001;167:4710-8.

17. Dorner T, Burmester GR. The role of B cells in rheumatoid arthritis: mechanisms and therapeutic targets. Curr Opin Rheumatol 2003;15:246-52

18. Tighe H, Carson DA. Rheumatoid factors. In: Kelley WN, Harris ED Jr, Ruddy S, Sledge CB, eds. Textbook of rheumatology. 5th ed. Vol. 1. Philadelphia: W.B. Saunders, 1997:241-9.

19. van Zeben D, Hazes JM, Zwinderman AH, Cats A, van der Voort EA, Breedveld FC. Clinical significance of rheumatoid factors in early rheumatoid arthritis: results of a follow up study. Ann Rheum Dis 1992;51: 1029-35.

20. Choy EHS, Panayi GS. Cytokine pathways and joint inflammation in rheumatoid arthritis. N Engl J Med 2001;344:907-16.

21. McLaughlin P, Hagemeister FB, GrilloLopez AJ. Rituximab in indolent lymphoma: the single-agent pivotal trial. Semin Oncol 1999;26:Suppl 14:79-87.

Copyright (c) 2004 Massachusetts Medical Society.

POWERPOINT SLIDES OF JOURNAL FIGURES

At the Journal's Web site, subscribers can automatically create PowerPoint slides of Journal figures. Click on a figure in the full-text version of any article at www.nejm.org, and then click on PowerPoint Slide for Teaching. A PowerPoint slide containing the image, with its title and reference citation, can then be downloaded and saved. 